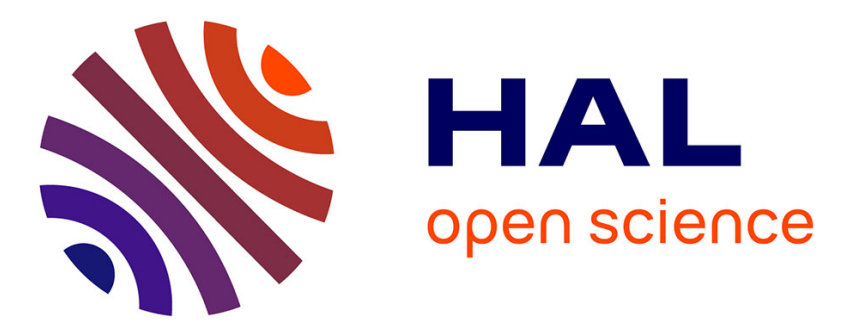

\title{
Low birefringent magneto-optical waveguides fabricated via organic-inorganic sol-gel process
}

F. Choueikani, F. Royer, S. Douadi, A. Skora, D. Jamon, D. Blanc, A. Siblini

\section{To cite this version:}

F. Choueikani, F. Royer, S. Douadi, A. Skora, D. Jamon, et al.. Low birefringent magneto-optical waveguides fabricated via organic-inorganic sol-gel process. European Physical Journal: Applied Physics, 2009, 47 (3), pp.1-8. 10.1051/epjap/2009096 . hal-00489487

\section{HAL Id: hal-00489487 https://hal.science/hal-00489487}

Submitted on 5 Jun 2010

HAL is a multi-disciplinary open access archive for the deposit and dissemination of scientific research documents, whether they are published or not. The documents may come from teaching and research institutions in France or abroad, or from public or private research centers.
L'archive ouverte pluridisciplinaire HAL, est destinée au dépôt et à la diffusion de documents scientifiques de niveau recherche, publiés ou non, émanant des établissements d'enseignement et de recherche français ou étrangers, des laboratoires publics ou privés. 


\title{
Low birefringent magneto-optical waveguides fabricated via organic-inorganic sol-gel process
}

\author{
F. Choueikani ${ }^{1}$, F. Royer ${ }^{1}$, S. Douadi ${ }^{2}$, A. Skora ${ }^{1}$, D. Jamon ${ }^{1}$, D. Blanc ${ }^{3}$ and A. Siblini ${ }^{1}$ \\ ${ }^{1}$ Laboratoire Dispositifs et Instrumentation en Optoélecronique et Microondes-EA3523, Université Jean Monnet, 23 rue Mich- \\ elon, 42023 Saint Etienne cedex 2, France. \\ 2 Laboratoire des Liquides Ioniques et Interfaces Chargées-UMR CNRS 7412, Université Pierre et Marie Curie, 4 place Jussieu, \\ 75252 Paris Cedex 05, France. \\ ${ }^{3}$ Laboratoire Hubert Curien-UMR CNRS 5516, Université Jean Monnet, 18 rue Benoît Lauras 42000 Saint Etienne, France.
}

Received: date / Revised version: date

\begin{abstract}
This paper is devoted to the study and the characterization of novel magneto-optical waveguides prepared via organic-inorganic sol-gel process. Thin silica/zirconia films doped with magnetic nanoparticles were coated on glass substrate using dip-coating technique. After annealing, samples were UV-treated. Two different techniques were used to measure their properties: m-lines spectroscopy and free space ellipsometry. Results evidence low refractive index waveguides that combine a low modal birefringence $\left(2 \times 10^{-4}\right)$ with a Faraday rotation around $15 \% \mathrm{~cm}(\phi=0.1 \%)$. The low birefringence is obtained with a soft UV treatement and a graded intrinsic anisotropy is evidenced for films thicker than $5 \mu \mathrm{m}$. Therefore, we prove that the organic-inorganic sol-gel approach is very promising to realize magneto-optical waveguides with a nonreciprocal functionality such as TE-TM mode conversion.
\end{abstract}

PACS. 78.66.Sq Composite materials - 78.20.Fm Birefringence - 78.20.Ls Magneto-optical effects

\section{Introduction}

Magneto-optical waveguides constitute the basic element to realize integrated devices that have a non reciprocal functionality such as optical isolator and circulator. Isolator stabilises laser oscillations by preventing the backward travelling light from re-entering into the laser cavity [1]. Circulators separate output and input ports in bidirectional data transmission [2]. Several components have already been made using magnetic Yttrium Iron Garnet (YIG) deposited on a Gadolinium Gallium Garnet (GGG) substrate. In spite of interesting properties [3], they cannot be easily integrated with standard fabrication technologies because of the high value of the annealing temperature of the magnetic iron garnet and because of the specific characteristics of GGG which is not commonly used in integrated optics technologies based on III-V semiconductor, silica, silicon and polymer [4]. Moreover, the garnet material possesses a high refractive index value $(\mathrm{n} \approx 2.2$ @ $1550 \mathrm{~nm}$ ). Thus, the single-mode condition imposes a thickness smaller than $1 \mu \mathrm{m}$ which leads to a non-efficient coupling into optical fibers [5]. Therefore, the development of new magneto-optical materials having a low refractive index $(\approx 1.5)$ and compatible with integration technologies is currently an active area of research [6]. Interesting ef-

Send offprint requests to: Fadi Choueikani

Correspondence to: fadi.choueikani@univ-st-etienne.fr fects have been demonstrated in semiconductor magnetic material [7]. In our work, we explore an alternative way to achieve magneto-optical thin films for the conception of integrated magneto-optical planar waveguides. They are made of magnetic nanoparticles doped silica-type matrix. This approach is justified by two main points:

- The low temperature process $\left(<120^{\circ}\right)$ used to realized thin films is fully compatible with integrated components technologies: no high temperature process is necessary to obtain the magneto-optical activity of the film.

- Contrary to classical magneto-optical thin films, this refractive index range is close to that of glass-type integrated components (1.5-1.6).

Previous results have shown the potentiality of such a material [8]. However, the magneto-optical conversion of the components was limited by a too important value of the matrix birefringence and by a too low intrinsic Faraday rotation of the nanoparticles [8]. In this article, we present the possibility to improve theses properties by using an organic-inorganic sol-gel matrix and cobalt ferrite $\left(\mathrm{CoFe}_{2} \mathrm{O}_{4}\right)$ nanoparticles. This paper is organised as follows: at first, we present the fundamental properties of magneto-optical waveguides; i.e. intrinsic Faraday rotation, phase mismatch and TE-TM mode conversion. Then, the process used to realize hybrid sol-gel films doped with cobalt ferrite nanoparticles is detailed. Characterization 
techniques are briefly presented. The main part deals with experimental results about the behavior of the refractive index, the index profile or the birefringence as a function of several parameters such as the zirconium rate, the kind of treatment and the film's thickness. Then, a qualitative observation of the light propagation is presented. The specific Faraday rotation is detailed later. Discussion and conclusion are finally given.

\section{Magneto-optical waveguides}

Magneto-optical functionality in planar waveguides is based on the non reciprocal polarization conversion observed on a light beam in a material submitted to a longitudinal magnetic field. This non reciprocal effect can be observed through the TE-TM mode conversion. The maximum rate of mode conversion is expressed as [9]:

$$
R=\frac{\theta_{F}^{2}}{\theta_{F}^{2}+(\Delta \beta / 2)^{2}}
$$

where $\theta_{F}(0 / \mathrm{cm})$ is the specific Faraday rotation of the material constituting the waveguide. $\Delta \beta(\% / \mathrm{cm})$ is the phase mismatch between TE and TM modes : $\Delta \beta=2 \pi \Delta$ $\mathrm{N}_{m} / \lambda$, where $\Delta \mathrm{N}_{m}$ is the difference between the TE and TM effective index for mode number $\mathrm{m}$, and $\lambda$ is the light wavelength. In the case of a planar waveguide that possesses a step index profile, this modal birefringence $\Delta \mathrm{N}_{m}$ is composed of a geometric birefringence $\Delta N_{\text {geo }}$ and an intrinsic birefringence $\Delta \mathrm{n}_{i}, \Delta \mathrm{N}_{m}=\left(\Delta \mathrm{N}_{\text {geo }}\right)_{m}+\Delta \mathrm{n}_{i}[10]$. $\Delta \mathrm{N}_{\text {geo }}$ finds its origin in the geometrical design of the waveguide. It increases with the mode number. It depends also on the film's thickness and on the difference between the refractive index of the film and the substrate [10]. $\Delta \mathrm{n}_{i}$ is the difference between TE and TM film's refractive index. It is due to the intrinsic residual stress in the sol-gel material. In our case, $\Delta \mathrm{N}_{\text {geo }}$ is relatively low compared to $\Delta \mathrm{n}_{i}$. Consequently, decreasing $\Delta \mathrm{n}_{i}$ is a way to reduce the modal birefringence $\Delta \mathrm{N}_{m}$ in order to improve the conversion efficiency.

\section{Synthesis and fabrication}

The sol-gel process is based on hydrolysis and condensation reactions of liquid precursors [11-13]. The sol described in this paper is composed of a photopolymerisable organically modified silicon alkoxide, zirconium alkoxide and methacrylic acid. Zirconium alkoxide is added to the solution for two reasons. Firstly, to vary the refractive index of the film in order to meet the fundamental waveguide condition : film's refractive index must be higher than the substrate's refractive index $\left(\right.$ Pyrex $^{T M}: \mathrm{n}=1.47 @ 633$ $\mathrm{nm})[14,15]$. Secondly, to improve the mechanical properties of the films such as the material elasticity that allows the realization of crack-free transparent coatings $[11,16]$. The elaboration of the thin films by the sol-gel process is reported on Fig.1.

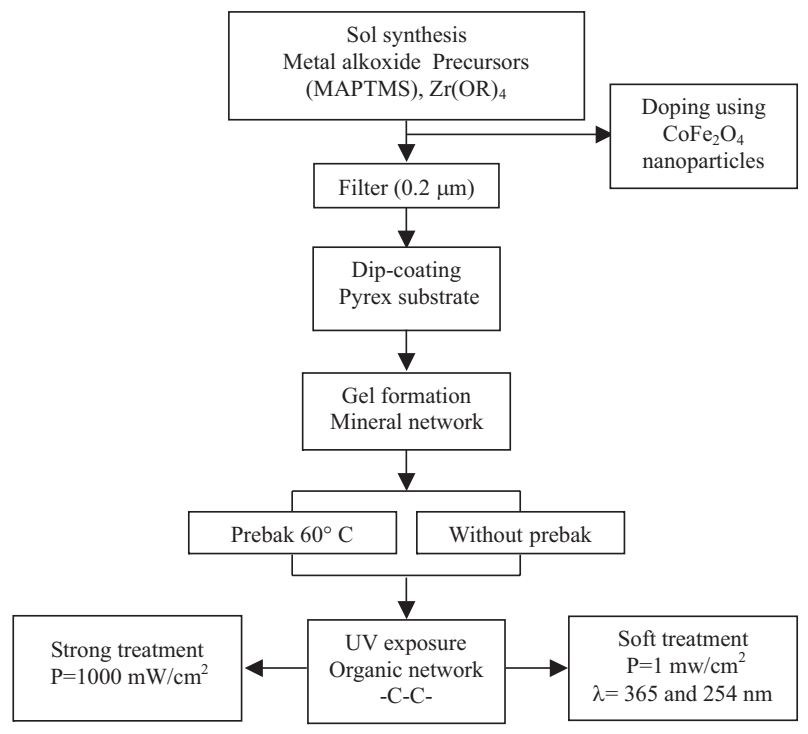

Fig. 1. Elaboration protocol of thin films.

The photopolymerisable silicon alkoxide, methacryloxy trimethoxysilane (MAPTMS 99\%/ $\mathrm{H}_{2} \mathrm{C}=\mathrm{C}\left(\mathrm{CH}_{3}\right) \mathrm{CO}_{2}\left(\mathrm{CH}_{2}\right)_{3}$ $\left.\mathrm{Si}\left(\mathrm{OCH}_{3}\right)_{3}\right)$ was partially hydrolyzed and condensed with an aqueous solution of hydrochloric acid $\left(10^{-2} \mathrm{M}\right)$ as a soft catalyst. The molar ratio of the water to the MAPTMS is 0.75 . As the zirconium precursor (normal zirconium propoxide $\mathrm{Zr}\left(\mathrm{OC}_{3} \mathrm{H}_{7}\right)_{4} / 70 \%$ wt. in 1-propanol) is very sensitive to water, it has to be complexed by methacrylic acid (MAA) to avoid precipitation. The molar concentration of the sol constituents respects the following proportion: 10: i: i ( $\mathrm{i}=1,2,3$ or 4 ). For exemple, 10:1:1 should be read as $10 \mathrm{~mol}$ MAPTMS, $1 \mathrm{~mol} \mathrm{Zr}(\mathrm{OR})_{4}, 1 \mathrm{~mol} \mathrm{MAA.}$ Prehydrolysed MAPTMS and complexed zirconium propoxide were stirred together for one hour. Hydrolysis and condensation of the remaining silicon alkoxide functionalities and zirconium propoxide was made by the addition of water. The molar ratio of the water to the silicon and zirconium alkoxide is 1.5. A photoinitiator (IRGACURE 651 / 2.2-dimethoxy-2-phenylacetophenone) was added to start the polymerisation under UV-light exposure. The molar concentration MAPTMS: IRGACURE is 1: 0.025 . Finally, to obtain a magneto-optical material, a magnetic fluid was added in the sol. It is made of Cobalt ferrite $\left(\mathrm{CoFe}_{2} \mathrm{O}_{4}\right)$ nanoparticles grafted with a gradient copolymer poly(sterene)-g-Poly(Acrylic Acid), PS-g-PAA in isopropyl alcohol/water solution in volume ratio of $0.7 / 0.3$. The mixture was passed through a $0.2 \mu \mathrm{m}$ filter in order to obtain a clear sol.

Pyrex $^{T M}$ substrates were rinsed in flowing distilled water. Rinsing with ethanol and drying with air completed the procedure. Using the dip-coating technique, thin films were deposited at different withdrawing speeds. Then, films were immediately prebaked at $60^{\circ} \mathrm{C}$ (or without prebaked and passed into next step) in air during 60 min to partially eliminate the organic residual in the mineral network. Finally, to lead to the creation of the organic network by photopolymerisation of the methacrylate 
groups (break the carbons double covalent bonds $\mathrm{C}=\mathrm{C}$ ), two possibilities exists for the UV-light exposure. The first is a strong treatment with a UV source light having a density of $1000 \mathrm{~mW} / \mathrm{cm}^{2}$ (ORIEL $350 \mathrm{~W}$ high-pressure mercury arc lamp). The second possibility is a soft treatment using a UV source light (UVLS-28 EL series UV Lamps) having a density of $1 \mathrm{~mW} / \mathrm{cm}^{2}$ for two wavelengths 365 $\mathrm{nm}$ and $254 \mathrm{~nm}$ respectively.

\section{Characterization techniques}

M-lines spectroscopy and ellipsometry are the two different techniques used to determine the optical and magnetooptical properties of waveguides such as the refractive index value and its profile, the thickness, the modal birefringence and the specific Faraday rotation. M-lines spectroscopy is a very precise technique to determine the refractive index of the films (the refractive index can be obtained with precision of $10^{-3}$ ) [17]. It consists in focusing a laser beam on a prism placed in contact with the film $[18,19]$. By application of a load to the prism, optical coupling into the film can be obtained for only particular angles. These angles are synchronous with the propagation modes: dark lines are thus observed in the light beam coming out from the prism. Using these synchronous angles, we can determine the mode effective indexes by the relation [20]:

$$
N_{m}=n_{p} \sin \left(A_{P}+\arcsin \left(\frac{\sin \theta_{m}}{n_{p}}\right)\right)
$$

where $\mathrm{n}_{p}$ and $\mathrm{A}_{p}$ are respectively the refractive index and the angle of the prism. The measurement of the effective index $\mathrm{N}_{T E}$ and $\mathrm{N}_{T M}$ gives the modal birefringence $\Delta \mathrm{N}_{m}=\left(\mathrm{N}_{T E}\right)_{m^{-}}\left(\mathrm{N}_{T M}\right)_{m}$. When the waveguide has two modes or more, the refractive index $\mathrm{n}_{T E}$ and $\mathrm{n}_{T M}$ and the film's thickness $\mathrm{h}$ can be determined, using a numerical adjustment based on a step refractive index profile [18]. Then, the intrinsic birefringence $\Delta \mathrm{n}_{i}$ can be also determined using the following formula: $\Delta \mathrm{n}_{i}=\mathrm{n}_{T E}-\mathrm{n}_{T M}$. Furthermore, the refractive index profile can be reconstructed from the $\mathrm{N}_{m}$ values by a numerical adjustment based on the Iterated Wentzel-Kramers-Brillouin method "IWKB" $[21,22]$. Ellipsometry is a free space analysis of the light state of polarization and allows the measurements of optical linear or circular anisotropy. In our case, a linearly polarized light is passed through the sample with a direction perpendicular to the film plane and under the influence of a longitudinal magnetic field. Thus, the Faraday effect induces a rotation of the state of polarization $\theta_{F}$. The determination of this angle is made with a null ellipsometer based on a sinusoidal Faraday modulator associated with a lock-in amplifier [23,24]. The high angle resolution $\left(0.001^{\circ}\right)$ of this null ellipsometer apparatus has allowed us to demonstrate the Faraday rotation of our samples whose thickness is around $5 \mu \mathrm{m}$.

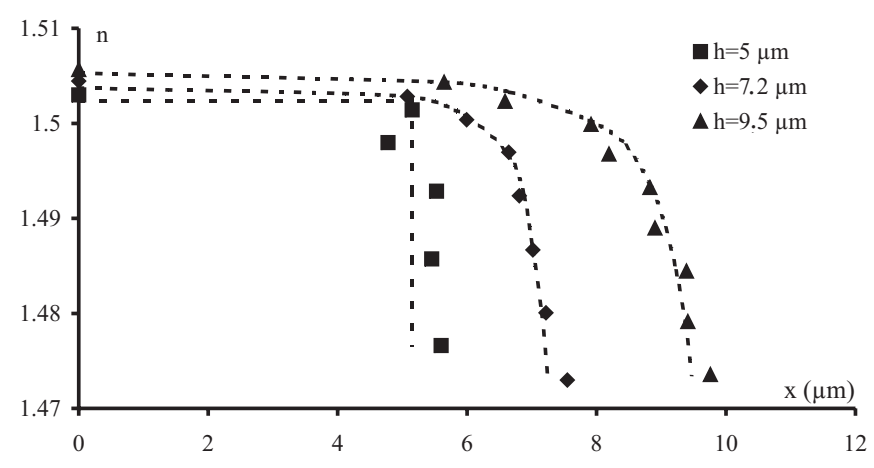

Fig. 2. Refractive index profile (refractive index versus depth $\mathrm{x})$ for three different thickness. Undoped samples were UVtreated, during $10 \mathrm{~min}$ for each wavelength. The power density of UV-light is $1 \mathrm{~mW} / \mathrm{cm}^{2}$. The measurements were made at $633 \mathrm{~nm}$.

\section{Experimental results}

\subsection{Refractive index}

The conception of waveguides for integrated photonic applications requires the control of their refractive index. Therefore, we are interested by the influence of the film's thickness on the index profile of the waveguide. Fig.2 illustrates three different index profiles. They correspond to three different film's thickness 5, 7.2 and $9.5 \mu \mathrm{m}$ obtained using three different withdrawing speeds. The index profiles construction were performed with the IWKB method, using the effective indices obtained by M-lines at $633 \mathrm{~nm}$.

This graph evidences the dependence of the refractive index profile on the film's thickness. Up to $5 \mu \mathrm{m}$, the waveguide has got a step index profile. Above $5 \mu \mathrm{m}$, the profile tends to be graded. The polymerization reaction under UV-treatment does not seem to be homogenous for high thickness. It may be due to the fact that UV-light cannot penetrate to the bottom of the film whose thickness is higher than $5 \mu \mathrm{m}[25]$. Therefore, the step refractive index profile's condition requires fabrication of thin films that have a thickness lower than $5 \mu \mathrm{m}$.

The refractive index evolution of silica/zirconia matrix versus zirconium rate in the solution is also reported on Fig.3. The results were obtained on undoped thin films which were UV treated during $30 \mathrm{~min}$, using a light source that has a power density of $1000 \mathrm{~mW} / \mathrm{cm}^{2}$. The measurements were performed using the M-lines spectroscopy at three different wavelength 633,820 and $980 \mathrm{~nm}$ Thus, the graph shows the refractive index for $9 \%$ (10:1:1), $17 \%$ (10:2:2) and $28 \%$ (10:4:4) of zirconium rate. It proves that increasing the zirconium concentration is a way to increase significantly the refractive index. This result is useful to adjust a refractive index value which satisfies the waveguiding condition.

The refractive index evolution versus UV-light exposure time is summarized in Fig.4. The samples were made of $10: 1: 1$ sol. They were prebaked at $60^{\circ} \mathrm{C}$ during $60 \mathrm{~min}$ and UV treated at $365 \mathrm{~nm}$ and $254 \mathrm{~nm}$ wavelength respectively with different exposure times. The UV-light 


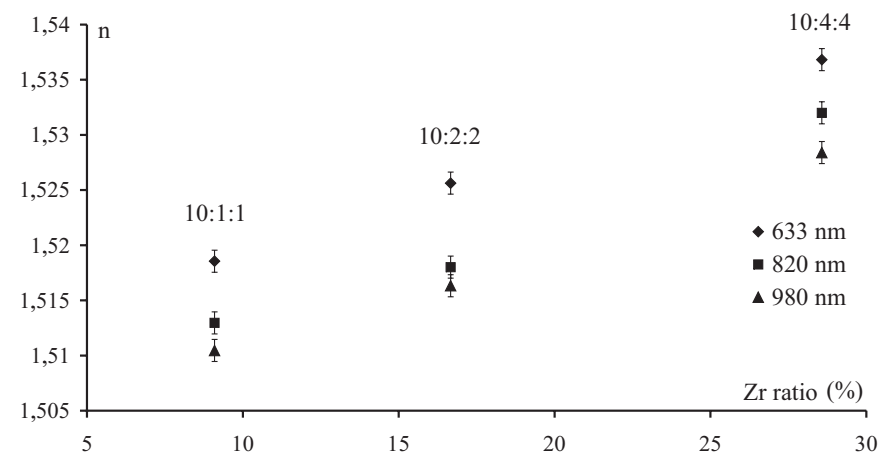

Fig. 3. Variation of the refractive index versus zirconium rate. Undoped samples were UV-treated during $30 \mathrm{~min}$, using the light source of $1000 \mathrm{~mW} / \mathrm{cm}^{2}$ of power density. The measurements were made using M-lines spectroscopy at 633, 820 and $980 \mathrm{~nm}$.

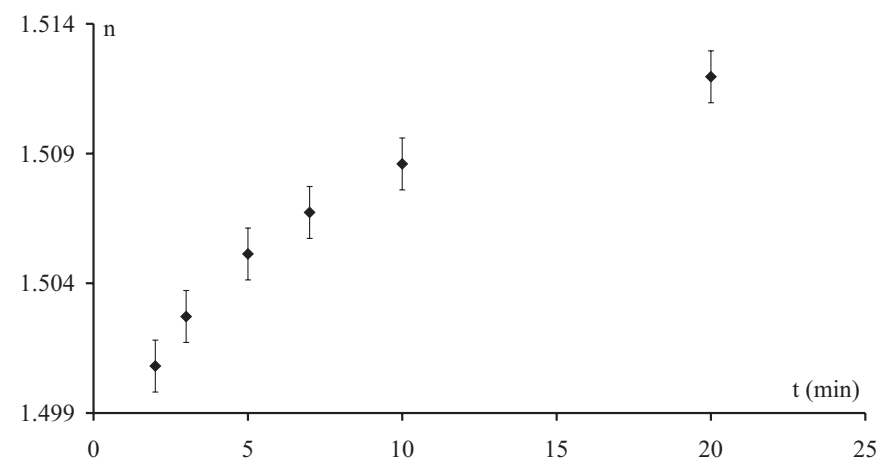

Fig. 4. Variation of the refractive index as a function of UVlight exposure time. Undoped samples were prebacked during $60 \mathrm{~min}$ at $60^{\circ} \mathrm{C}$. The measurements were performed with Mlines spectroscopy at $633 \mathrm{~nm}$.

presents a low power density which is $1 \mathrm{~mW} / \mathrm{cm}^{2}$. Finally, the samples that possess a thickness around $5 \mu \mathrm{m}$ were characterized using M-lines spectroscopy at $633 \mathrm{~nm}$.

At 2 min of UV-light exposure for each wavelength, the refractive index of the film was measured to be 1.5. Increasing UV-exposure time, the refractive index of the film's waveguide increases, reaching its maximum value of 1.512 after $20 \mathrm{~min}$ for each wavelength. This evolution of the refractive index is due to the polymerization of the organic network under UV-light exposure. After 20 min for each wavelength of UV-light exposure, the refractive index keeps its maximum value and remains constant. The result is typically similar to that reported by $[26,27]$.

The effect of the sol-gel layers aging on the film refractive index was also studied. Three undoped samples were UV-treated at $365 \mathrm{~nm}$ and $254 \mathrm{~nm}$ respectively during three different exposure times : 2, 7 and $20 \mathrm{~min}$ for each wavelength.

The variation of the film's index as a function of layers aging (number of days after deposition) for different exposure times are depicted in Tab.1. This table indicates that during 18 days, the refractive index of the film UV-treated for a short duration such as 2 and $7 \mathrm{~min}$ is increased, while
Table 1. Evolution of the refractive index versus age of films that were UV-treated at three different durations. Undoped samples were prebaked at $60^{\circ} \mathrm{C}$ during $60 \mathrm{~min}$. The measurements were made using M-lines spectroscopy at $633 \mathrm{~nm}$.

\begin{tabular}{lrrr}
\hline \hline Age & UV-exposure time & & \\
& $2 \mathrm{~min}$ & $7 \mathrm{~min}$ & $20 \mathrm{~min}$ \\
\hline 0 day & 1.500 & 1.506 & 1.511 \\
18 days & 1.508 & 1.509 & 1.511 \\
26 days & 1.508 & 1.509 & 1.511 \\
\hline
\end{tabular}

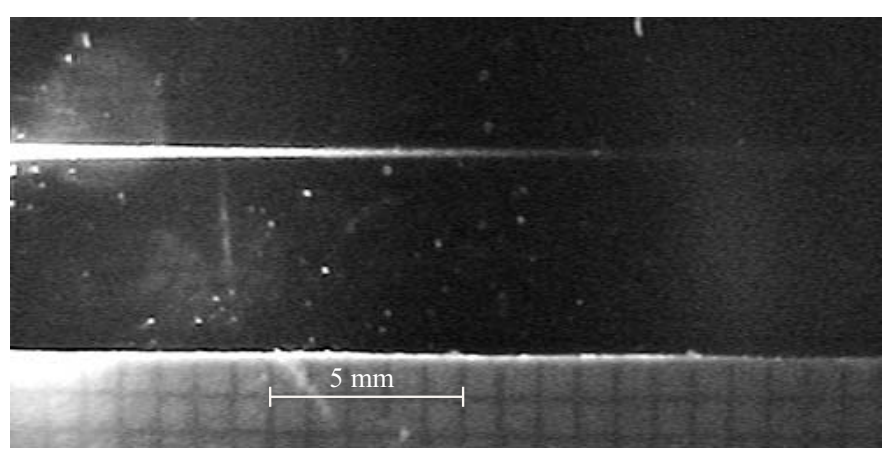

Fig. 5. The light propagation into a doped waveguide, at 820 $\mathrm{nm}$. The sample was UV-treated at $1000 \mathrm{~mW} / \mathrm{cm}^{2}$ during 30 min. The photo was taken with a CCD camera.

those treated during 20 min for each wavelength remains approximately constant. After 8 more days, the refractive index of each of the three samples keeps the same value. For a short duration of UV-treatment, polymerization reaction cannot be finalized. Then, during theses 26 days film was exposed to a natural light and the polymerization reaction continued to lead to the formation of the organic network. In summary, realizing a waveguide that has an invariable refractive index requires soft $\mathrm{UV}$ treatment (1 $\mathrm{mW} / \mathrm{cm}^{2}$ ) during $20 \mathrm{~min}$ for each wavelength.

\subsection{Propagation loss}

The optical quality of waveguides can be checked by visualizing of the light propagation.

Fig. 5 presents the photo of the light propagation in a doped sample. The sample was UV-treated during $30 \mathrm{~min}$, using the light source of $1000 \mathrm{~mW} / \mathrm{cm}^{2}$. The light was coupled into the thin layer using a prism coupling apparatus and photo was taken by a CCD camera. The photo proves the absence of cracks and defects which can damage the light propagation. Moreover, it shows a distance of light propagation around $1.5 \mathrm{~cm}$. The organic network adds a flexibility to the global organic-inorganic matrix constituting the waveguide. Thus, the waveguide presents a good optical quality and is cracks free even if it is thick [16].

\subsection{Birefringence}

As mentioned in the second section, the TE-TM mode conversion is affected by the birefringence. A specific study 
Table 2. Variation of the intrinsic birefringence $\Delta \mathrm{n}_{i}$ as a function of UV-light exposure time. Undoped films were prebaked at $60^{\circ} \mathrm{C}$ during $60 \mathrm{~min}$. Strong and soft should be read respectively as $1000 \mathrm{~mW} / \mathrm{cm}^{2}$ and $1 \mathrm{~mW} / \mathrm{cm}^{2}$ of power density.

\begin{tabular}{lcc}
\hline $\begin{array}{c}\text { Kind of } \\
\text { UV-treatment }\end{array}$ & $\begin{array}{c}\text { UV } \\
\text { exposure time }\end{array}$ & $\begin{array}{c}\text { Intrinsic } \\
\text { Birefringence }\end{array}$ \\
\hline Strong & $15 \mathrm{~min}$ & $6 \times 10^{-4}$ \\
Soft & $5 \mathrm{~min}$ & $1 \times 10^{-5}$ \\
Soft & $10 \mathrm{~min}$ & $2 \times 10^{-5}$ \\
Soft & $20 \mathrm{~min}$ & $2.5 \times 10^{-4}$ \\
\hline
\end{tabular}

has been leaded to minimize this parameter. Therefore, the evolution of the intrinsic birefringence $\Delta \mathrm{n}_{i}$ versus power density and UV-exposure time is reported in Tab.2. The samples were respectively strongly UV-treated

$\left(1000 \mathrm{~mW} / \mathrm{cm}^{2}\right)$ during $15 \mathrm{~min}$ and softly UV-treated (1 $\mathrm{mW} / \mathrm{cm}^{2}$ ) during 5, 10, and $20 \mathrm{~min}$ for each wavelength. The measurements were made at $633 \mathrm{~nm}$, using M-lines spectroscopy.

The table proves that the birefringence of the material depends on the UV light power and exposure time. The increase of theses two parameters induces an increase of the film's birefringence. In magneto-optical waveguides, one needs to reduce this birefringence. To do so, UV light power and exposure time should be reduced as much as possible. But, according to the results of section 5.1, a too short UV time exposure will lead to unfinalized layer and moving refractive index. So, using a soft treatment during a long duration of UV-treatment such as 20 min for each wavelength is the way to realize the better samples, with a birefringence around $2 \times 10^{-4}$ and a stabilized index.

To complete this study, it appeared interesting to work precisely on the influence of the film's thickness on the birefringence. Two samples were particularly tested, these samples having extremum values of their thickness: $4.8 \mu \mathrm{m}$ and $13 \mu \mathrm{m}$. For each sample, the evolution of the measured modal birefringence has been plotted as a function of the mode number, and their refractive index profile has been calculated using the IWKB method. The results are gathered respectively in fig. 6 and fig.7, for the $4.8 \mu \mathrm{m}$ and 13 $\mu \mathrm{m}$ sample. The fig. 6 shows, for the thinner sample, that the modal birefringence increase as a function of the mode number, and the refractive index has a step index profile $(\mathrm{n} \approx 1.515$ and $\mathrm{h}=4.8 \mu \mathrm{m})$. This increase of the modal birefringence is identical to that of the geometric birefringence calculated using the obtained value of $\mathrm{n}$ and $\mathrm{h}$, and for each mode one can write $\Delta \mathrm{N}_{m}=\left(\Delta \mathrm{N}_{g e o}\right)_{m}+\Delta \mathrm{n}_{i}$ with a constant value of the intrinsic birefringence $\Delta \mathrm{n}_{i}=2 \times 10^{-4}$. Thus, the refractive index and the anisotropy of the film are homogenous.

The thicker sample has very different behavior. Indeed, the evolution of the modal birefringence, reported on fig.7, evidences that it remains almost constant for each mode, and that the refractive index possesses a graded index profile. Based on this graded profile, the geometric birefringence has been calculated using the WKB method and plotted on the fig.8. The graph shows that it increases as

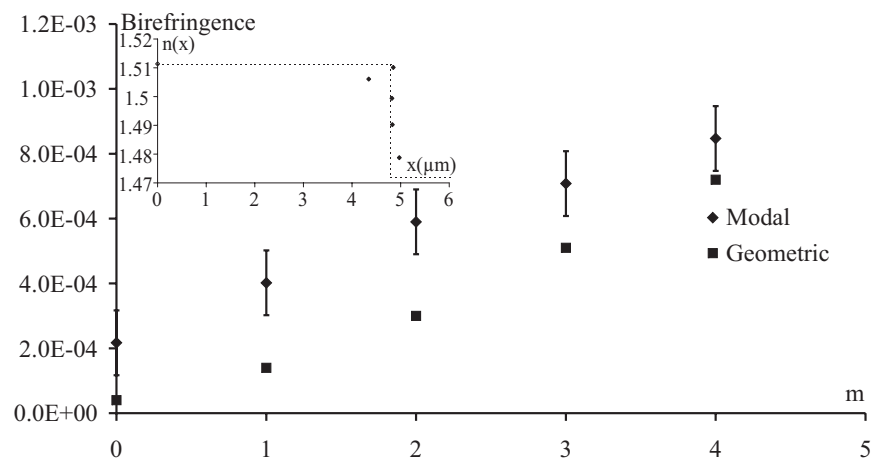

Fig. 6. Evolution of the measured modal birefringence versus mode number $\mathrm{m}$ for an undoped sample that has a thickness around $4.8 \mu \mathrm{m}$. The graph in the inset presents the sample's step index profile determined by IWKB (see Fig.1).

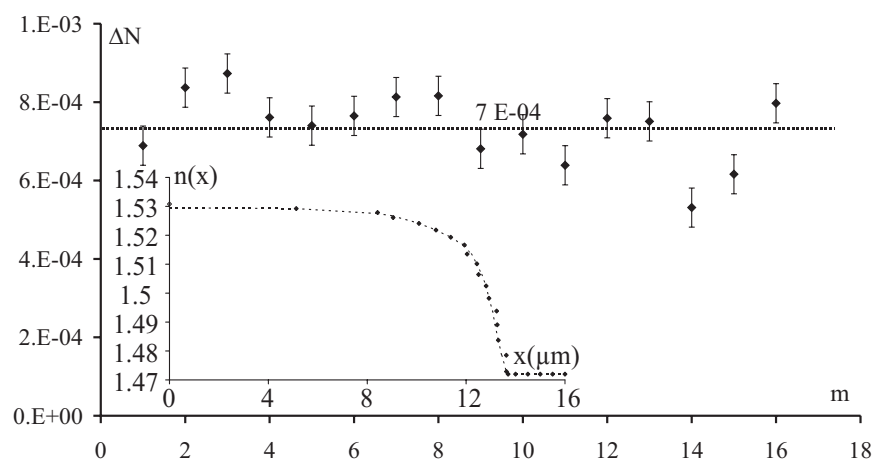

Fig. 7. Variation of the modal birefringence as a function of the mode number $\mathrm{m}$ for the thicker undoped sample $(\mathrm{h}=13$ $\mu \mathrm{m})$. The graph in the inset presents the sample's graded index profile.

a function of the mode number, with an evolution really different to that of the measured modal birefringence.

As a consequence, the simple equation $\Delta \mathrm{N}=\Delta \mathrm{N}_{g e o}+\Delta \mathrm{n}_{i}$ can not be written for each mode with a constant value of $\Delta \mathrm{n}_{i}$. Based on the idea that the energy of modes with low $\mathrm{m}$ is much more confined close to the surface that the energy of modes with large $\mathrm{m}$, we have supposed that his film should possess an intrinsic birefringence whose value decreases with the film depth. Such a graded anisotropy is depicted in fig.9.

Using this graded anisotropy and the graded index profile, the modal birefringence has been calculated for each mode with the WKB method and the results are reported on fig.10. This graph shows a quite-invariant value of the modal birefringence: $6.9 \times 10^{-4}$, in qualitative good agreement with the experimental value of fig. $7\left(7 \times 10^{-4}\right)$.

Therefore, this specific study proves that the invariant value of the modal birefringence is due to the intrinsic birefringence which decreases as a function of the film depth. This result is consistent with those obtained on the influence of the UV treatment on the refractive index: the power density of the UV light irradiation diminishes with 


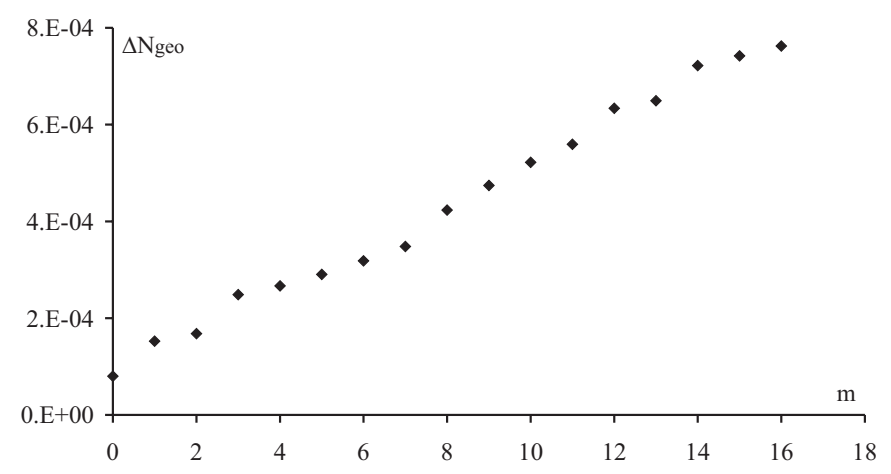

Fig. 8. Evolution of the geometric birefringence, calculated with the WKB method for the graded profile, as a function of the mode number $\mathrm{m}$.

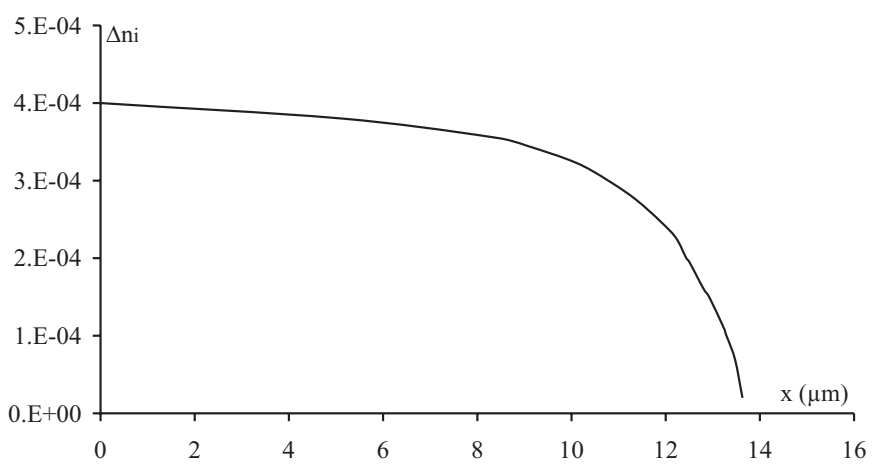

Fig. 9. Variation of the theoretical model of the intrinsic birefringence as a function the film's depth.

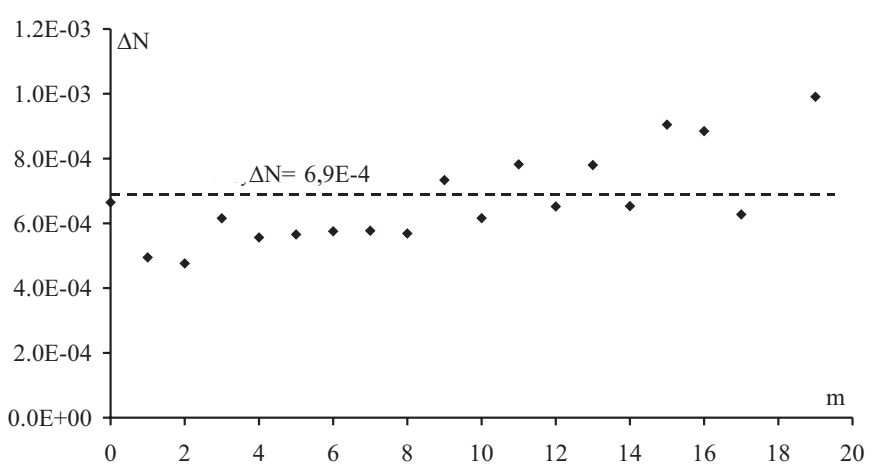

Fig. 10. Variation of the calculated modal birefringence as a fucntion of $\mathrm{m}$. Assuming a graded index profile and a graded anisotropy (fig.9), the modal birefringence of the thicker sample was calculated using the WKB method.

the film's depth, so, the less are the refractive index and the intrinsic birefringence.

Finally, to obtain a film completely finalized with an homogenous index and an homogenous and small birefringence, we should use a long but soft UV treatment associated to a thickness less than $5 \mu \mathrm{m}$.
Table 3. The birefringence of the fundamental mode and its composition mineral and organic-inorganic sol-gel film. The mineral film was thermal treated at $500{ }^{\circ} \mathrm{C}$ during $30 \mathrm{~min}$. The Strong organic-inorganic film was Thermal and UV treated with a light source of $1000 \mathrm{~mW} / \mathrm{cm}^{2}$. The soft organic-inorganic film was dried at $60{ }^{\circ} \mathrm{C}$ during $60 \mathrm{~min}$ and UV-treated during $20 \mathrm{~min}$ for each wavelength with a power density of $1 \mathrm{~mW} / \mathrm{cm}^{2}$.

\begin{tabular}{llll}
\hline & $\begin{array}{c}\text { Mineral } \\
\text { (without UV) }\end{array}$ & $\begin{array}{c}\text { Organic-inorganic } \\
\text { Strong UV }\end{array}$ & $\begin{array}{c}\text { Organic-inorganic } \\
\text { Soft UV }\end{array}$ \\
\hline $\mathrm{n}$ & 1.57 & $1.5-1.54$ & $1.5-1.54$ \\
$\mathrm{~h}$ & $1.9 \mu \mathrm{m}$ & $3-6 \mu \mathrm{m}$ & $3-6 \mu \mathrm{m}$ \\
\hline$\Delta \mathrm{N}_{0}$ & $3.7 \times 10^{-3}$ & $6 \times 10^{-4}$ & $3 \times 10^{-4}$ \\
$\Delta \mathrm{N}_{\text {geo }}$ & $3 \times 10^{-4}$ & $1 \times 10^{-5}$ & $1 \times 10^{-5}$ \\
$\Delta \mathrm{n}_{i}$ & $3.4 \times 10^{-3}$ & $5.9 \times 10^{-4}$ & $2.9 \times 10^{-4}$ \\
\hline
\end{tabular}

\subsection{Comparison between hybrid and mineral sol-gel film}

Table 3 presents a simple comparison of the intrinsic birefringence of waveguides elaborated via organic-inorganic hybrid sol-gel process and those made of mineral sol-gel process (studied by F. Royer et al. [8]). It also gives a composition of the fundamental modal birefringence $\Delta N_{0}$ in geometrical part $\Delta N_{g e o}$ and intrinsic part $\Delta n_{i}$, assuming a homogenous intrinsic anisotropy. The mineral thin films were fabricated from a sol-gel preparation of non photopolymerisable methyltriethoxysilicate (MTEOS) and tetrabuthylorthotitanate $\left(\mathrm{Ti}(\mathrm{OBu})_{4}\right)$ with a mixed solution of $\mathrm{C}_{2} \mathrm{H}_{5} \mathrm{OH}$ and diluted $\mathrm{HCl}$ (see [8] for details).

This table confirms that, in each case, the geometrical birefringence is relatively low compared to the intrinsic one and that the intrinsic birefringence is the source component of the modal birefringence (around $\Delta \mathrm{N}_{0}$ ). The main result is that the intrinsic birefringence of soft treated hybrid matrix is ten times lower than that of pure mineral one: around $3 \times 10^{-4}$ compared to $3 \times 10^{-3}$. This point is really important to realize magneto-optical mode conversion in a waveguide.

\subsection{Faraday rotation}

Fig. 11 reports the Faraday rotation of a hybrid sol-gel thin film doped with cobalt ferrite nanoparticles $\left(\mathrm{CoFe}_{2} \mathrm{O}_{4}\right)$. It has been measured using the free space ellipsometry at $820 \mathrm{~nm}$ wavelength. This value is known to give the large magnitude of the Faraday rotation combined with a good transparency of cobalt ferrite nanoparticles [28]. The doped sample was made of one sol-gel layer deposited on Pyrex $^{T M}$. It was UV-treated during 30 min, using a power density of $1000 \mathrm{~mW} / \mathrm{cm}^{2}$. Its refractive index and its thickness were measured using the M-lines spectroscopy. They are respectively 1.525 and $2.9 \mu \mathrm{m}$ thick.

The obtained curve has a nonreciprocal behavior typical of the Faraday effect. The saturated magnitude at high field is about $15 \% / \mathrm{cm}$. This value indicates that the volume fraction of nanoparticles in the film is about $0.1 \%$. 


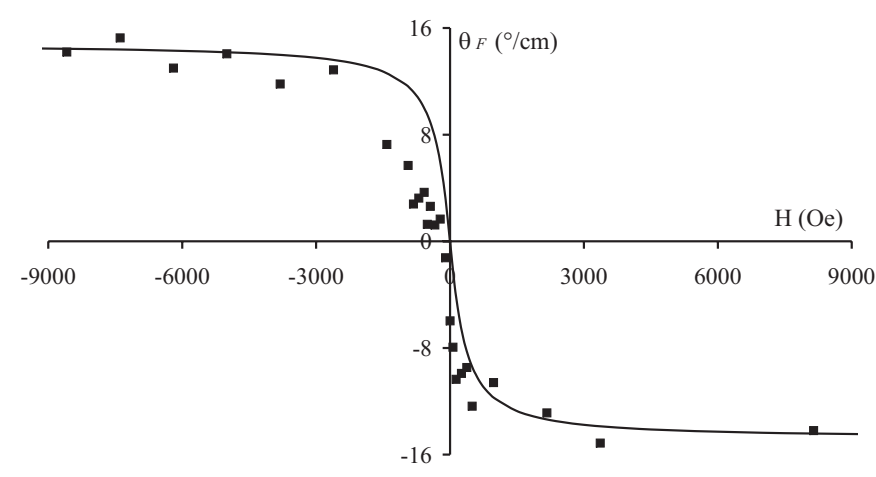

Fig. 11. The specific Faraday rotation of a $2.9 \mu \mathrm{m}$ thick sample versus longitudinal applied magnetic field. The sample was strongly UV-treated during $30 \mathrm{~min}$. The measurement were performed using free space elliprometry at $820 \mathrm{~nm}$. Points are experimental measurements. The line is a guide for the eyes with a langevin behavior.

In order to evaluate the magneto-optical capacities of the matrix doped by $\mathrm{CoFe}_{2} \mathrm{O}_{4}$ nanoparticles, we calculate the figure of merit which is expressed as :

$$
\frac{\theta_{F}}{\alpha}
$$

where $\theta_{F}\left({ }^{\circ} / \mathrm{cm}\right)$ and $\alpha\left(\mathrm{cm}^{-1}\right)$ are respectively the specific Faraday rotation and the loss coefficient. For a loss coefficient around $8 \mathrm{~dB} / \mathrm{cm}$, measured by a gray-scale analysis (see section 5.2), the figure of merit value is evaluated at $2^{\circ}$.

Previous results have shown a Faraday rotation about $29 \% / \mathrm{cm}$ for a $2 \%$ maghemite nanoparticles volume fraction in thin films elaborated via mineral sol-gel process [8]. They, have also shown a figure of merit for the nanoparticules that varies between $0.3^{\circ}$ and $0.8^{\circ}$ [29]. By comparison, our lasts results confirm that organic-inorganic sol-gel films doped by cobalt ferrite are very promising to realize a magneto-optical waveguide. Furthermore, these results demonstrate the capacity to realize magneto-optic material whose refractive index is close to that of many optical components 1.52 . This property is a key parameter to realize highly compatible magneto-optical waveguide.

\section{Discussion}

Our study proves that metallic oxide thin films made by an hybrid organic-inorganic sol-gel process and doped by cobalt ferrite nanoparticles present a magneto-optical activity. Theses films have a low modal birefringence of the order of $2 \times 10^{-4}$ for the fundamental mode. This value is ten times lower than that of precedent films made of a pure mineral matrix [16]. To obtain such a low birefringence a special attention has been paid to the treatment parameters. Best results are obtain with a long but soft UV exposure. This kind of treatment gives a low intrinsic birefringence $\Delta \mathrm{n}_{i}$ combined with a finalized and stable thin films. Compared to pure mineral matrix, organic network adds to the flexibility of the film [16], and serves to reduce the intrinsic birefringence $\Delta \mathrm{n}_{i}$. Such films should be used as TE-TM mode converter, which is the basic element of optical isolators. But, for the time being, the magnitude of the expected conversion is two low to be used in a component : $\mathrm{R}=0.2 \%$ with $\theta_{F}=15^{\circ} / \mathrm{cm}, \Delta \mathrm{N}=2 \times 10^{-4}$ and $\lambda=820 \mathrm{~nm}$. However, this value is around hundred times higher than the expected value of mineral thin film doped with Maghemite nanoparticles : $\mathrm{R}=0.2 \%$ to be compared to $\mathrm{R}=0.01 \%$ [8]. The difference is mainly due to the lower modal birefringence of organic-inorganic thin films. This improvement of the value of the expected TE-TM conversion is really rewarding and shows that this way to realize magneto-optical conversion is promising. The current value of the expected conversion is limited by the too low particle volume fraction in the film, $\phi=0.1 \%$, which gives a saturated intrinsic Faraday rotation of $\theta_{F}=15^{\circ} / \mathrm{cm}$. In order to achieve a TE-TM conversion value about ten per cent or more, the volume fraction $\phi$ should be increased to a value of the order of $1-2 \%$. This is the subject of ongoing works led by the research team.

\section{Conclusion}

We have described the fabrication of low index magnetooptical planar waveguides on Pyrex ${ }^{T M}$ substrate. Films are composed of an organically modified silica/zirconia matrix doped by cobalt ferrite nanoparticles. The refractive index, the birefringence and the specific Faraday rotation were measured. The influence of several elaboration parameters have been studied. The results demonstrate that the magneto-optical activity of the films is around $15 \% / \mathrm{cm}$. It is associated to a low modal birefringence $\left(2 \times 10^{-4}\right)$. This low value is due to the use of an organicinorganic matrix treated with a long but soft UV exposure. However, the expected TE-TM conversion is too low to be used in an integrated components. In order to improve the properties of these waveguides, the nanoparticles volume fraction has to be increased. This is the subject of ongoing works.

\section{References}

1. T. Amemiya, H. Shimizu, M. Yokoyama, P. N. Hai, M. Tanaka, and Y. Nakano. Appl. Opt. 46, (2007) 57845791.

2. A. Saib, M. Darques, L. Piraux, D. Vanhoenacker-Janvier, and I. Huynen. J. Phys. D : Appl. Phys. 38 (2006) 27592763.

3. N. Bahlmann, M. Lohmeyer, O. Zhuromskyy, H. Dotsch, and P. Hertel. Opt. Comm. 161 (1999) 330-337.

4. D. C. Hutchings. J. Phys. D: Appl. Phys. 36 (2003) 22222229.

5. R. Wolfe, J. Hegarty, L. C. Lutter, and D. L. Wood. Appl. Phys. Lett. 48 (1986) 508-510.

6. S. Muto and Y. Tatsuzawa. Poly. Adv. Tech. 11 (2000) 597-600.

7. M. C. Debnath, V. Zayets, and K. Ando. Appl. Phys. Lett. 91 (2007) 043502. 
8. F. Royer, D. Jamon, J. J. Rousseau, H. Roux, D. Zins, and V. Cabuil. Appl. Phys. Lett. 86 (2005) 011107.

9. W. Zaets and K. Ando. Appl. Phys. Lett. 77 (2000) 15931595.

10. H. Dammann, E. Pross, G. Rabe, W. Tolksdorf, and M. Zinke. Appl. Phys. Lett. 49 (1986) 1755-1757.

11. L. C. Klein, editor. Sol-gel optics : Processing and applications (Kluxer Academic Publishers, London 1994).

12. A. Moujoud and S. I. Andrews, M. P.and Najafi. J. Sol-gel Sci. Tech. 35 (2005) 123-126.

13. A. Moujoud, Z. Sadikki, T. Touam, and S. I. Najafi. Thin Solid Films 422 (2002) 161-165.

14. A. W. Snyder and W. R. Young. J. Opt. Soc. Am. 68 (1978) 297-309.

15. H. F. Taylor and A. Yariv. Proceedings of the IEEE 62 (1974) 1044-1060.

16. S. Sakka and H. Kozuka, editors. Chapter 15 of Handbook of sol-gel science and technology-Volume I: Sol-gel processing (Kluwer academic publ., 2005).

17. S. Monneret, P. Huguet-Chantome, and F. Flory. J. Opt. A: Pure Appl. Opt. 2 (2000) 188-195.

18. R. Ulrich and R. Torge. Appl. Opt. 12 (1973) 2901-2908.

19. P.K. Tien and R. Ulrich. J. Opt. Soc. Am. 60 (1970) 13251337.

20. E. Pelletier, F. Flory, and Y. Hu. Appl. Opt. 28 (1989) 2918-2924.

21. E. Acosta, M. V. Gato, L. Perez, and C. Gomez-Reino. Pure Appl. Opt. 4, (1995) 485-493.

22. J. M. White and P. F. Heidrich. Appl. Opt. 15(1976) 151155.

23. R. M. A. Azzam and N. M. Bashara, editors. Ellipsometry and Polarized light (Elsevier science, Amsterdam 1987).

24. J. Monin, H. Sahsah, and O. Brevet-Philibert. Thin Solid Films 234 (1993) 408-411.

25. T. M. Lovestead, A. K. OŠBrien, and C. N. Bowman. Journal of photochemistry and photobiology A: chemistry $\mathbf{1 5 9}$ (2003) 135-143.

26. P. Coudray, J. Chisham, M. P. Andrews, and S. I. Najafi. Opt. Eng. 36 (1997) 1234-1240.

27. T. Touam, G. Milova, Z. Saddiki, M. A. Fardad, M. P. Andrews, J. Chrostowski, and S. I. Najafi. Thin solid films 307 (1997) 203-207.

28. F. Donatini, D. Jamon, J. Monin, and S. Neveu. IEEE Trans. Magn. 35 (1999) 4311-4317.

29. F. Royer, D. Jamon, J. J. Rousseau, V. Cabuil, D. Zins, H. Roux, and C. Bovier. Eur. Phys. J.: App. Phys. 22 (2003) 83-87. 